\title{
Hypertension Drug Suitability Evaluation Based on Patient Condition with Improved Profile Matching
}

\author{
Hari Soetanto, Sri Hartati, Retyanto Wardoyo, Samekto Wibowo \\ Universitas Gadjah Mada, Sekip utara, Bulak sumur, Yogyakarta, Indonesia
}

\begin{tabular}{l} 
Article Info \\
\hline Article history: \\
Received Jan 2, 2018 \\
Revised Feb 23, 2018 \\
Accepted Mar 6, 2018 \\
\hline
\end{tabular}

Keywords:

Drug suitability

Hypertension

Profile matching

Interpolation

\begin{abstract}
The accuracy of the type or dosage of drugs by doctors is important. The types and doses of medicines given by the doctors should match the illness suffered by the patient as well as consider the patient's health condition. In hypertension disease, the error rate of drug dosage by medical personnel is quite high, reaching 34\%. Meanwhile, the administration of the type and dosage of drugs appropriate to the patient's condition required the knowledge of high medical personnel and experienced medical personnel. In this research, we developed the model of drug suitability evaluation with hypertension patient's health condition using Profile Matching method. The proposed model evaluates the patient's health condition based on the parameters provided by the expert and produces recommendations on the type of drug. To optimize the Profile Matching method, in this research we applied interpolation weighting method which calculates the proximity level of the patient profile with drug profile more accurately. Based on the experiment, the proposed model has an accuracy value of $87 \%$, precision $87.11 \%$ and recall of $85.44 \%$. It proves that the proposed method can provide recommendations on the right type of hypertension medication. Also, the interpolation weighting method is proven to increase the accuracy.
\end{abstract}

Copyright (c) 2018 Institute of Advanced Engineering and Science. All rights reserved.

\section{Corresponding Author:}

Hari Soetanto, Universitas Gadjah Mada, Sekip utara, Bulak sumur, Yogyakarta, Indonesia.

Email: hari.soetanto@budiluhur.ac.id

\section{INTRODUCTION}

Hypertension or high blood until now still be the number one killer disease in Indonesia [1]. The disease not only affects adult people due to degenerative factors but attacks people in productive age [2] Cardiovascular disease is the third largest disease of all deaths in the world, and hypertension is a major risk factor for the prevalence of cardiovascular disease.

Treatment of hypertensive patients can be done in two ways, namely by modifying the lifestyle and using antihypertensive drugs. Treatment of hypertensive patients with lifestyle modification is to maintain a normal weight, low-salt diet, and saturated fat, eat fruits and vegetables, reduce smoking and alcohol, and increase physical activity with exercise. Patients with hypertension can also use the approach through antihypertensive drugs. Anti-hypertensive medications given pay attention to age, history of the disease, smoking habits, obesity, and should consider the presence of diseases such as diabetes, kidney, heart failure and ischemic heart [3].

The use of inappropriate anti-hypertensive drugs often leads to complaints or side effects such as fever, diarrhea, diabetes, kidney failure, stress, oral breathing, nerve abnormalities, radiation in the neck and head, and localized disorders of the salivary glands. Drugs are the most common cause of reduced saliva. Antihypertensive drugs include one class of drugs that can cause side effects of xerostomia. It is therefore very important to know and recognize the type of antihypertensive drugs [4]. 
Incorrect drug dosage is a common case in patients with hypertension. Table 1, shows the results of studies showing the inaccuracy of dosage delivery when administering anti-hypertensive drugs [5]. Research shows that $34 \%$ of the administration of antihypertensive drugs by medical personnel is not exactly the dose. It has implications on the results of hypertension treatment process that is not complete or occur counterindication in patients.

Table 1. Doses evaluation of administration anti-hypertensive drugs [5]

\begin{tabular}{lllll}
\hline No. & anti-hypertensive drugs & Not Appropriate Dosage & Appropriate Dosage & amount \\
\hline 1. & Furosemida (diuretic) & 18 & 34 & 52 \\
2. & Captopril (AceI) & 23 & 11 & 34 \\
3. & Nifedipine (Beta Blocker) & 3 & 20 & 23 \\
4. & Valsartan (ARB) & 0 & 12 & 12 \\
5. & Lisinopril (AceI) & 1 & 6 & 7 \\
6. & Clonidin & 0 & 2 & 2 \\
7. & Amlodipin (CCB) & 0 & 3 & 3 \\
& TOTAL & 45 & 88 & 133 \\
\hline
\end{tabular}

Administration of anti-hypertensive drugs that is appropriate to the patient's condition requires high pharmacological knowledge. In fact, not all hospitals have enough pharmacologists to serve all patients. Therefore, the provision of anti-hypertensive drugs suitable for the patient's condition needs to be assisted by a computer system. Some studies proposed a computer-based system to help medical personnel or hypertension patients, such as [6]-[8]. In [6], Gusti et al. proposed expert systems for diagnosing hypertension based on patient's physical characteristics and the patient's lifestyle using C5.0 algorithms and fuzzy logic.

This study developed a computer-based system for evaluation of the suitability of anti-hypertensive drugs based on the patient's condition. The method used in this research is Profile Matching with the interpolation weighting. This evaluation model resulted in providing an anti-hypertensive drug suitable for the patient's condition.

\section{THE PROPOSED METHOD}

In this study, the phases of developing an evaluation model of the suitability of anti-hypertensive drugs as presented in Figure 1. Development stage consists of the first Stage of making a knowledge base involving input data from the hospital, expert knowledge and knowledge derived from literature studies

The second stage is the process of evaluation of the fit between the condition of the patient with the type of anti-hypertensive drugs. The method used is Profile Matching method.

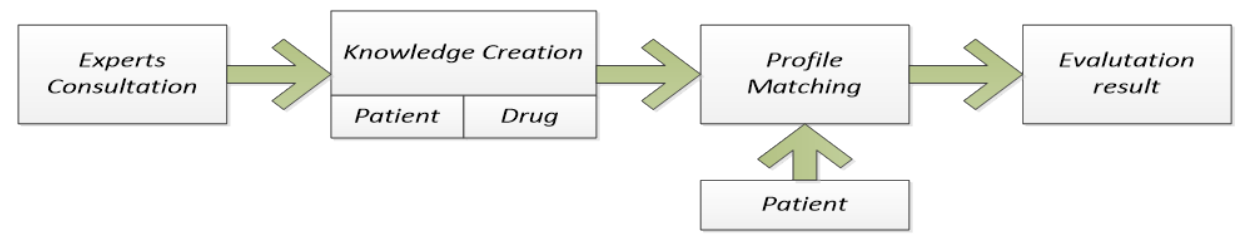

Figure 1. Phase evaluation model of conformity of drug with patient condition

\subsection{The Knowledge Base Stage}

At the stage of making knowledge carried out a series of processes involving experts in the field of hypertension and also based on input data. Experts or medical personnel use medical records of hypertensive patients to determine the criteria used as a reference of the type of drug that is appropriate to the patient's health condition.

\subsubsection{Determination of Types of Hypertension Drugs and Patient Parameters}

Experts evaluate the relationship between types of hypertensive drugs with the patient's health condition. There are 5 (five) types of hypertension drugs that have been identified, namely Diuretic, Beta Blocker, Ace Inhibitor, Calcium Channel Blocker (CCB) and Angiotensin Receptor Blocker (ARB). 
The results of consultation with the expert doctor showed that there are 10 (ten) parameters that determine the administration of antihypertensive drugs in hypertensive patients. These criteria are age, weight, kidney health level, lung health level, blood sugar level, blood circulation level, heart health level, depression level, uric acid level and sexuality level, as shown in Table 2.

Table 2. Parameters of the patient condition that influence hypertension drug administration

\begin{tabular}{|c|c|c|c|c|c|c|c|c|c|}
\hline age & weight & $\begin{array}{l}\text { Level of } \\
\text { kidney } \\
\text { health }\end{array}$ & $\begin{array}{l}\text { level of } \\
\text { lung } \\
\text { health }\end{array}$ & $\begin{array}{l}\text { level of } \\
\text { sugar } \\
\text { content }\end{array}$ & $\begin{array}{l}\text { level of arterial } \\
\text { blood } \\
\text { circulation }\end{array}$ & $\begin{array}{l}\text { level of heart } \\
\text { health }\end{array}$ & $\begin{array}{l}\text { depression } \\
\text { level }\end{array}$ & $\begin{array}{l}\text { Levels } \\
\text { of uric } \\
\text { acid }\end{array}$ & Sexuality \\
\hline year & BMI & $\mathrm{mg} / \mathrm{dl}$ & $\mathrm{ppm}$ & $\mathrm{mg} / \mathrm{dl}$ & liter & pulse/minute & Hamilton & $\mathrm{mg} / \mathrm{dl}$ & ordinal \\
\hline
\end{tabular}

Here is a brief description of each of the patient's health parameters:

1. The age parameter was obtained based on the patient's birth date data for subsequent age in a year.

2. The weight parameter is calculated based on patient's height and weight data. High values and weight gain value of BMI (body mass index)

3. Level of kidney health in units of $\mathrm{mg} / \mathrm{dl}$. The level of kidney health is obtained based on the laboratory examination performed on the patient.

4. The level of lung health is expressed in units of ppm. This value is obtained based on laboratory examination.

5. The level of sugar content expressed in mg/dl obtained by laboratory examination or examination using a blood glucose examiner.

6. The level of arterial blood circulation describes the smooth circulation of blood in the human circulatory system. The value of this parameter is expressed in liters and is calculated using laboratory tests.

7. The level of heart health can be calculated based on the number of times the heart beats within 1 minute. This value can be obtained by checking the patient's pulse rate and counting for 1 minute.

8. Examination obtains the depression level by the Hamilton method [9].

9. Levels of uric acid are expressed in $\mathrm{mg} / \mathrm{dl}$ and calculated by laboratory tests.

10. Sexuality is expressed on an ordinal scale with values below normal, normal and above normal.

\subsubsection{Patient Condition Match Assessment with Type of Anti Hypertension Drug}

To evaluate the suitability of the condition of the patient with the type of hypertensive medication required data. Data is ideal for ten parameters indicating the suitability of administration of certain types of anti-hypertensive drugs. For example for the administration of diuretic drugs: age less than 65, weight between 18.5 to 24.9 BMI scale, kidney health level between 0.6 to 1.2, lung health levels less than 4, levels of sugar between 60 to 139, blood circulation levels more than 6, a heart health level of more than 100, depression levels greater than 35, uric acid levels between 2 to 7.5 and an above normal level of sexuality, as well as for other types of drugs as shown in Table 3. This table is used for reference to determine the value of parameters to evaluate the suitability of the patient's condition with the type of hypertension medication, using Profile Matching evaluation method.

Table 3. Ideal parameter data for hypertensive drug type

\begin{tabular}{|c|c|c|c|c|c|c|c|c|c|c|}
\hline Type of Drug & Age & weight & $\begin{array}{c}\text { kidney } \\
\text { health level }\end{array}$ & $\begin{array}{l}\text { lung health } \\
\text { levels }\end{array}$ & $\begin{array}{c}\text { levels of } \\
\text { sugar }\end{array}$ & $\begin{array}{c}\text { blood } \\
\text { circulation } \\
\text { levels }\end{array}$ & $\begin{array}{c}\text { heart health } \\
\text { level }\end{array}$ & $\begin{array}{l}\text { depression } \\
\text { levels }\end{array}$ & $\begin{array}{l}\text { uric acid } \\
\text { levels }\end{array}$ & sexuality \\
\hline Diuretic & $\leq 65$ & $18,5-24,9$ & $0,6-1,2$ & $<4$ & $60-139$ & $>6$ & $>100$ & $\geq 35$ & $2-7,5$ & up normal \\
\hline Beta Blocker & $\leq 65$ & $18,5-24,9$ & $>1,2$ & $<4$ & $60-139$ & $>6$ & $60-100$ & $\leq 35$ & $>7,5$ & Normal \\
\hline ACE Inhibitor & $>65$ & $\geq 25$ & $>1,2$ & $\geq 4$ & $\geq 140$ & $>6$ & $>100$ & $>35$ & $>7,5$ & Normal \\
\hline CCB & $\leq 65$ & $\geq 25$ & $>1,2$ & $\geq 4$ & $\geq 200$ & $5-6$ & $>100$ & $\geq 35$ & $>7,5$ & Up normal \\
\hline
\end{tabular}

\subsection{Match Evaluation Of Patient Condition With Type of Anti Hypertension Drug}

Profile Matching method is one of the methods in decision support system. In principle, this method displays a decision recommendation based on the proximity level of the profile or data tested with an ideal condition. The proximity level of a test profile with an ideal profile is weighted and accumulated for the entire profile. In general, the weighting method used is ordinal weighting [10]-[14]. In this research, we use weighting with linear interpolation because patient condition parameter data have a value which is in a certain range. 

algorithm:

The evaluation of the patient's suitability with the type of drug in the process follows the following

1. Assessment of parameters

2. Weighting patient parameters for each type of drug

3. Calculation of the suitability of the patient's condition with the type of drug

\subsubsection{Parameter Rating}

The assessment for each parameter uses up, down and trapezoid interpolation [15]. The calculation of the parameter values rises following the rising interpolation curve, as illustrated in Figure 2.

In Figure 2 it shows that the value of the parameter $\mathrm{x}$ will be closer to the max value when the value of $\mathrm{x}$ is close to $\mathrm{d} 2$. Conversely, the value of $\mathrm{x}$ will be close to the min value when the value is away from $\mathrm{d} 2$ or close to d1. The weight value of $\mathrm{x}$ can be calculated by the interpolation equation as seen in Equation (1).

$$
\mathrm{W}(\mathrm{x})=\frac{\mathrm{x}-\mathrm{d} 1}{\mathrm{~d} 2-\mathrm{d} 1}(\max -\min )+\min
$$

with

1. $\mathrm{W}(\mathrm{x})$ is the weight value for input value $\mathrm{x}$

2. $\mathrm{x}$ is the parameter value for the test data

3. $\mathrm{d} 1$ is the minimum value range, and $\mathrm{d} 2$ is the maximum value range of the parameter

4. max value is the specified maximum value, and min value is the minimum value specified

In this study, the parameters assessed in the range of 0 to 5 . For example, the age parameters have an assessment of 0 to 5. For example for the parameters of the age of hypertensive patients, 65 years under the value of 5 while 65 with 85 follow the interpolation curve decreases as in Equation (1), with d1 $=65$ and $\mathrm{d} 2=85$. For the depression level parameter, it is 5 if the depression level is greater than 35 while 0 to 35 follows the rising interpolation curve as in Figure 3. The weight value of $\mathrm{x}$ can be calculated by the interpolation equation as seen in Equation (2).

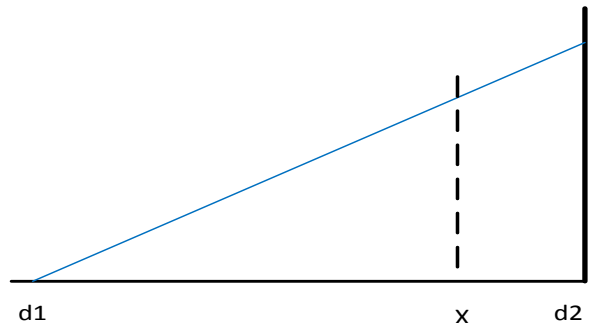

Figure 2. The interpolation curve is increases

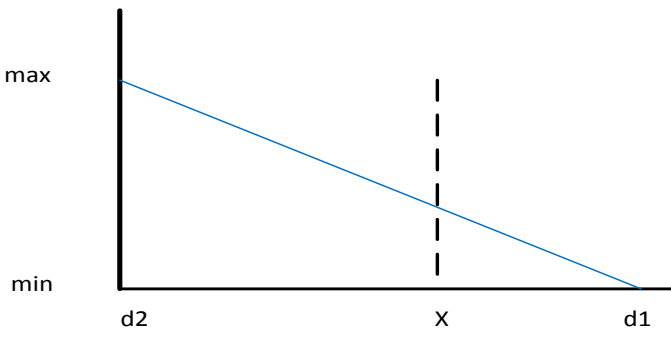

Figure 3. The interpolation curve decreases

$$
\mathrm{W}(\mathrm{x})=\frac{\mathrm{x}-\mathrm{d} 1}{\mathrm{~d} 2-\mathrm{d} 1}(\min -\max )+\max
$$

with:

1. $\mathrm{W}(\mathrm{x})$ is the weight value for input value $\mathrm{x}$

2. $\mathrm{x}$ is the parameter value for the test data

3. $\mathrm{d} 1$ is the minimum value range, and $\mathrm{d} 2$ is the maximum value range of the parameter

4. max value is the specified maximum value, and min value is the minimum value specified

\subsubsection{The Weighting of Patient Parameters for Each Drug Type}

Weighted patient parameters for each type of drug were performed based on the ideal profile value of each parameter that was verified by the expert (see Table 5). Weighting is formulated using the linear interpolation method as described in the previous sub-chapter. Curve and weighting function equations for each drug type and patient health parameters can be seen in Table 4. The weight values of patient parameters for each drug type were calculated based on the equations in each table. The weight value will reach the maximum value when the ideal condition is reached, and the interpolated weights will be calculated if it is beyond the ideal value. Especially for sexuality level parameter is not done interpolation weighting, but using ordinal weighting because the data form already in ordinal form. 
Table 4. Patient parameter values for drug type Diuretics

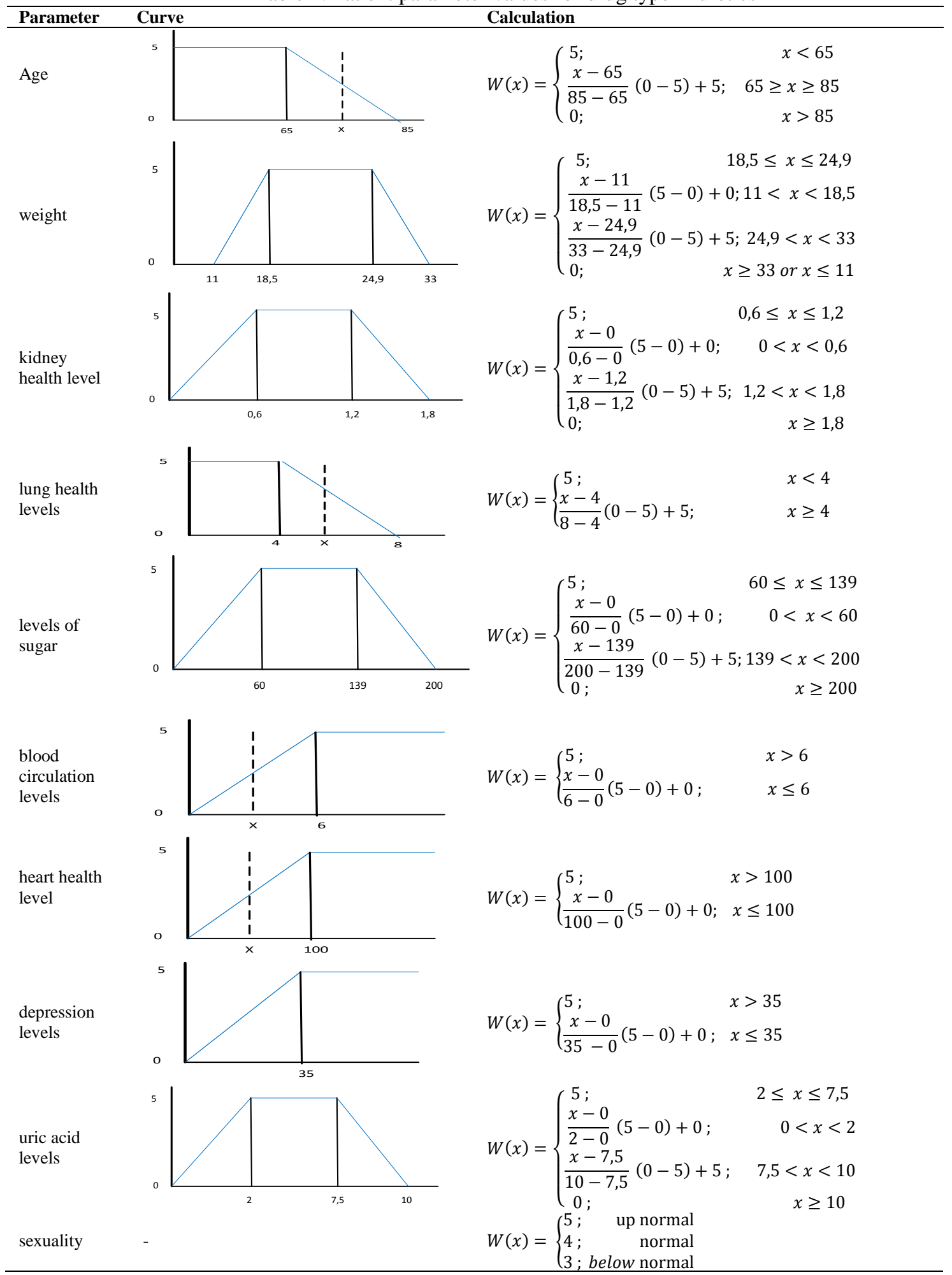

\subsubsection{Calculation of matching condition of Patient with Drug Type}

To calculate the patient's condition match with certain drug type, data of patient's condition parameter are age, weight, level of kidney health, level of lung health, level of sugar, blood circulation level, heart health level, depression level, uric acid level and sexuality level. Parameter parameters according to the expert doctor is divided into parameters of core factor and secondary factor. Core factor is a group of key parameters in which the determination of a given drug type depends heavily on the parameters in this group. 
While the secondary factor is a group of parameters that do not have a strong influence on the determination of the type of drug given to hypertensive patients. As shown in Table 6, the core factor gives influence 75 there is an evaluation of the suitability of patient condition with the type of drug, secondary factor influence 25 percent.

Table 5. Parameters of core factor and secondary factor

\begin{tabular}{clll}
\hline Core Factor & \multicolumn{2}{c}{ Secondary Factor } \\
\hline 1. & Kidney health level & 1. & Age \\
2. & Levels of sugar & 2. & weight \\
3. & Blood circulation levels & 3. & Lung health levels \\
4. & Heart health level & 4. & Depression levels \\
5. & Uric acid levels & 5. & Sexuality \\
\hline
\end{tabular}

Based on the data from the patient calculated the value of each parameter using linear interpolation curve (interpolation rise, interpolation down or combination). For example patient parameters data and calculation result value of parameter value shown in Table 6 and Table 7.

Table 6. Calculation of diuretic drug weight for patients

\begin{tabular}{lcccccccccc}
\hline Patient & Age & weight & $\begin{array}{c}\text { kidney } \\
\text { health } \\
\text { level }\end{array}$ & $\begin{array}{c}\text { lung health } \\
\text { levels }\end{array}$ & $\begin{array}{c}\text { levels of } \\
\text { sugar }\end{array}$ & $\begin{array}{c}\text { blood } \\
\text { circulation } \\
\text { levels }\end{array}$ & $\begin{array}{c}\text { heart } \\
\text { health } \\
\text { level }\end{array}$ & $\begin{array}{c}\text { depression } \\
\text { levels }\end{array}$ & $\begin{array}{c}\text { uric acid } \\
\text { levels }\end{array}$ & $\begin{array}{c}\text { sexuality } \\
\text { Budi }\end{array}$ \\
Value & 76 & 17 & 1,5 & 7,3 & 95 & 11 & 114 & 19 & 6 & Below normal \\
\hline
\end{tabular}

Table 7. Calculation W(x) of patient 'budi'

\begin{tabular}{lcl}
\hline \multicolumn{1}{c}{ Budi } & Data & Calculation \\
\hline Age & 76 & $\mathrm{~W}(\mathrm{x})=\frac{76-65}{85-65}(0-5)+5=2,25$ \\
weight & 17 & $\mathrm{~W}(\mathrm{x})=\frac{17-11}{18,5-11}(5)=4$ \\
kidney health level & 1,5 & $\mathrm{~W}(\mathrm{x})=\frac{1,5-1,2}{1,8-1,2}(0-5)+5=0,5$ \\
& 7,3 & $\mathrm{~W}(\mathrm{x})=\frac{7,3-4}{8-4}(0-5)+5=0,825$ \\
lung health levels & 95 & $\mathrm{~W}(\mathrm{x})=5$ \\
$\begin{array}{l}\text { levels of sugar } \\
\text { blood circulation }\end{array}$ & 11 & $\mathrm{~W}(\mathrm{x})=5$ \\
levels & 114 & $\mathrm{~W}(\mathrm{x})=5$ \\
heart health level & 19 & $\mathrm{~W}(\mathrm{x})=\frac{19-0}{35-0}(5)=2,714$ \\
depression levels & 6 & $\mathrm{~W}(\mathrm{x})=5$ \\
$\begin{array}{l}\text { uric acid levels } \\
\text { Sexuality }\end{array}$ & $\mathrm{W}(\mathrm{x})=3$ \\
\hline
\end{tabular}

Next calculated the difference in the value of the parameter value of the patient and the value of the ideal parameter value for a particular drug. For example, the difference between the value of the parameter in Table 8 with the value of the ideal parameter of the diuretic drug type is shown in Table 3.

Table 8. The Difference of the ideal and actual weight of patient

\begin{tabular}{lcccccccccc}
\hline & Age & weight & & $\begin{array}{c}\text { kidney } \\
\text { health level }\end{array}$ & $\begin{array}{c}\text { lung health } \\
\text { levels }\end{array}$ & $\begin{array}{c}\text { levels of } \\
\text { sugar }\end{array}$ & $\begin{array}{c}\text { blood } \\
\text { circulation } \\
\text { levels }\end{array}$ & $\begin{array}{c}\text { heart } \\
\text { health level }\end{array}$ & $\begin{array}{c}\text { depression } \\
\text { levels }\end{array}$ & $\begin{array}{c}\text { uric acid } \\
\text { levels }\end{array}$ \\
sexuality \\
Diuretic & $\leq 65$ & $18,5-24,9$ & $0,6-1,2$ & $<4$ & $60-139$ & $>6$ & $>100$ & $\geq 35$ & $2-7,5$ & up normal \\
Budi & 2,25 & 4 & 0,5 & 0,825 & 5 & 5 & 5 & 2,714 & 5 \\
\hline
\end{tabular}

By using the difference table and the weight table value of the calculated value of the parameters weights the parameters, the results are shown in the results table. The result of calculation of weight value calculated mean weight value of core factor parameters (Kidney health level, sugar level, arterial blood 
circulation level, cardiac health level, uric acid level) and secondary core factor (Age, Weight, Lung health level, Level of depression, Sexuality)

1. The weighted average value of the core factor parameters

$$
\mathrm{NCF}=\frac{0,5+5+5+5+5}{5}=4,1
$$

2. Weighted average value of Secondary Factor parameters

$$
\mathrm{NSF}=\frac{2,25+4+0,825+2,714+3}{5}=2,5578
$$

Furthermore, the value of evaluating the suitability of patients with the type of drug diuretics by taking into account the effect of core factors and secondary factors as follows:

Appraisal evaluation value $=0,75 \times \mathrm{NCF}+0,25 \times \mathrm{NSF}$

$$
=0,75 \times 4,1+0,25 \times 2,5578=3,71445
$$

These results indicate that patients with conditions as indicated in the patient data table if given a type of antihypertensive drug diuretic have a match $(3.71445 / 5) \times 100 \%=74.28 \%$. In the same way as the above can be evaluated the suitability of another patient. The results of the evaluation of the condition of the patient's condition with various types of anti-hypertensive drugs are shown in Table 9.

Table 9. Results of the patient matching rate for each type of antihypertensive medication

\begin{tabular}{cccccc}
\hline & Diuretic & Beta Blocker & ACE Inhibitor & CCB & ARB \\
\hline Budi & $74,28 \%$ & $73,774 \%$ & $\mathbf{8 7 , 2 9 \%}$ & $65,48 \%$ & $66,98 \%$ \\
\hline
\end{tabular}

Thus the model can evaluate the suitability of the patient's condition with various types of antihypertensive drugs as discussed in the results and analysis

\subsubsection{Determination of Drug Recommendations}

The total value of the calculation of the suitability level of the drug type and the patient's health parameters are then sorted from the largest to the smallest. The type of drug with the order of the first match rate (the greatest total value) is recommended to be given because it is most suitable for the patient's health condition. However, all calculations are presented so that doctors and medical personnel can determine based on their level of expertise and experience.

\section{RESULTS AND ANALYSIS}

This chapter describes the results of tests and discussions based on test results that have been done.

\subsection{Testing Accuracy, Precision, and Recall}

Test results on the proposed model that includes the calculation of accuracy, precision and recall value shows the performance of the proposed model is quite good. The test is done in 2 (two) stages by involving different experts. Each test was performed using 100 test data. Table 10 and Table 11 display the test results in the form of confusion matrix for each test phase. In the first stage of testing it appears that for most test data, the system can determine the drug type appropriately. For example, according to expert doctors, of all test data (patient data), there are 39 data that should be given Diuretic drugs, and according to

\begin{tabular}{|c|c|c|c|c|c|}
\hline & \multicolumn{5}{|c|}{ PREDICTED LABEL } \\
\hline & $\mathrm{ARB}$ & ACE INHIBITOR & BETA BLOCKER & $\mathrm{CCB}$ & DIURETIC \\
\hline ARB & 9 & 0 & 0 & 1 & 0 \\
\hline 崇BETA BLOCKER & 0 & 1 & 21 & 0 & 7 \\
\hline 次 & 1 & 0 & 0 & 4 & 0 \\
\hline
\end{tabular}
the system 36 of which are recommended with the right type of drug.

Table 10. The confusion matrix testing of the first stage 
In the second stage test results, where the verification of the test was done by different experts from the first test, it can be seen that from all test data (patient) there are 38 people who according to the expert should be given the type of Diuretic drug. The system can also present appropriate recommendations for those 38 data. It shows that the proposed method can provide good recommendations.

Table 11. The confusion matrix testing of the second stage

\begin{tabular}{|c|c|c|c|c|c|}
\hline & \multicolumn{5}{|c|}{ PREDICTED LABEL } \\
\hline & ARB & ACE INHIBITOR & BETA BLOCKER & $\mathrm{CCB}$ & DIURETIC \\
\hline ARB & 10 & 0 & 0 & 0 & 0 \\
\hline ACE INHIBITOR & 1 & 16 & 2 & 0 & 1 \\
\hline PETA BLOCKER & 0 & 1 & 20 & 0 & 4 \\
\hline 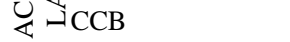 & 1 & 0 & 1 & 5 & 0 \\
\hline DIURETIK & 0 & 0 & 0 & 0 & 38 \\
\hline
\end{tabular}

Table 10 and Table 11, can then be calculated the value of accuracy, precision, and recall of the proposed method as shown in Figure 4. From the two stages of testing, obtained an average accuracy of $87 \%$, precision $87.11 \%$ and recall $85.44 \%$. The accuracy value indicates that as many as $87 \%$ of the system can provide correct drug delivery recommendations. The value of precision and recall is also at a value more or less equal to the value of accuracy. This indicates that for patient data that should be given certain drugs, the system can provide the drug recommendations appropriately.

\subsection{Comparison of Ordinal Weights and Interpolation}

In this study, we propose the interpolation weighting method as described in the previous chapter. To see the performance of the interpolation method, a comparison with the ordinal method is a classical weighting method in Profile Matching method. Figure 4 presents the results of the comparison of the accuracy, precision and recall values of the interpolation weighting method with ordinal weighting.

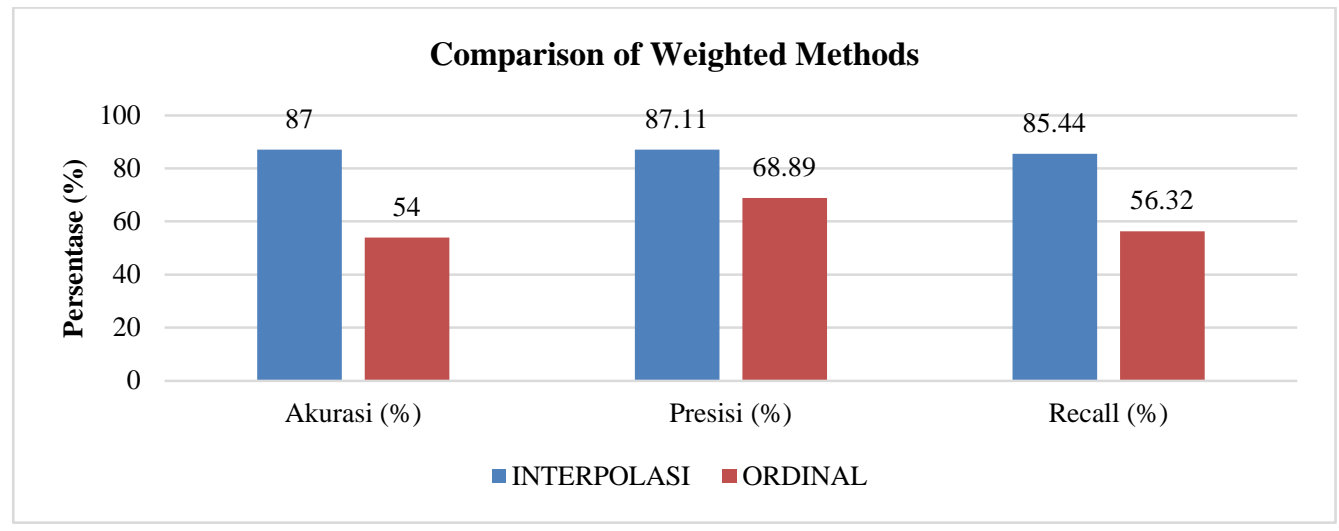

Figure 4. Comparison of accuracy, precision and recall method profile matching with weighting interpolation and ordinal weighting

Figure 4 shows that the accuracy, precision and recall value of the Profile Matching method is higher when the interpolated weights are applied, compared to the $54 \%$ ordinal weighting method. In the interpolated weights, the accuracy value increased by $87 \%$ compared to the ordinal method. This may occur because, in the interpolated weighting method, the resulting weight value is more accurate because it uses a proportionally weighted formula. Meanwhile, on ordinal weighting, the weight value is determined constantly (fixed). Figure 5 presents a comparative example of determining the weighting of blood sugar level parameters using ordinal and interpolated weights. From the figure, we can see that interpolation weighting method will produce more flexible weight, than ordinal weighting method. 


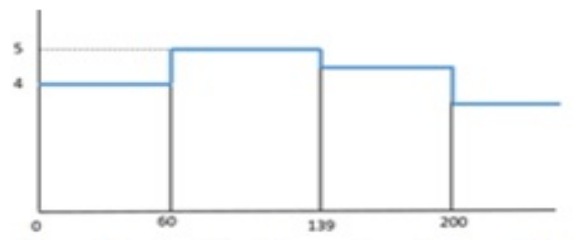

(a) weighting blood sugar levels by ordinal weighting method

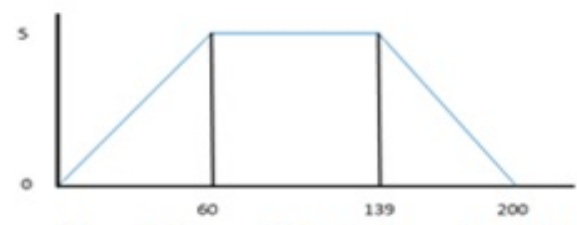

(b) weighting of blood glucose level by interpolated weighting method

Figure 5. Comparison of weight parameter determination of blood sugar level using ordinal and interpolation weighting method

\section{CONCLUSION}

Based on the description, explanation and testing have been done, obtained some conclusions. This study produced a model of conformity of drug delivery evaluation based on the patient's health condition using Profile Matching method. Based on the results of evaluation and testing of the proposed model, obtained an accuracy of $87 \%$, precision $87.11 \%$ and recall of $85.44 \%$. The proposed model uses Profile Matching method with interpolated weights. Tests show that the application of interpolated weights succeeded in increasing the accuracy value by $87 \%$ compared to ordinal weighting method.

Nevertheless, this research still needs to be continued considering it still has some weaknesses and shortcomings. The profile matching method is expected to be enhanced by applying the fuzzy method in the weighting process. This research needs to be developed by comparing the performance of profile matching methods and other intelligent system methods such as AHP, neural networks, and data mining.

\section{REFERENCES}

[1] Pusdatin Kemkes, “Hipertensi: The Silent Killer,” kemkes.go.id, 2015. [Online]. Available: http://www.pusdatin.kemkes.go.id/article/view/15080300001/hipertensi-the-silent-killer.html. [Accessed: 01-Jan2017].

[2] Herlambang, Menaklukan Hipertensi dan Diabetes: mendeteksi, mencegah dan mengobati dengan cara medis dan herbal, 1st ed. Yogjakarta: Tugu Publisher, 2013.

[3] L. Hadyanto, Farmakologi Kardiovaskuler, 2nd ed. Jakarta: PT. Softmedia, 2009.

[4] C. Fox, P. L. Kalarickal, M. J. Yarborough, and J. Y. Jin, "Perioperative management including new pharmacological vistas for patients with pulmonary hypertension for noncardiac surgery.," Curr. Opin. Anaesthesiol., vol. 21, no. 4, pp. 467-472, 2008.

[5] W. Supadmi, "Evaluasi Penggunaan Obat Anti Hipertensi Evaluation of Drug Use in Anti Hypertension Patients Who Chronic Renal Failure Undergo Hemodialysis,” J. Ilm. Kefarmasian, vol. 1, no. 1, pp. 67-80, 2011.

[6] I. Gusti, M. Ngurah, A. Yasa, K. Gede, D. Putra, N. M. Ika, and M. Mandenni, "Hypertension Expert System with C5.0 Algorithm and Fuzzy Logic,” TELKOMNIKA (Telecommunication, Computing, Electronics and Control), vol. 12, no. 7, pp. 5669-5677, 2014.

[7] S. H. Dai, G. Ying, and X. Q. Zhu, "Design of the intelligent real-time hypertensive diagnosis expert system based on web,” Proc. - Int. Symp. Inf. Process. ISIP 2008 Int. Pacific Work. Web Min. Web-Based Appl. WMWA 2008, pp. 252-256, 2008.

[8] A. A. Abdullah, Z. Zakaria, and N. F. Mohamad, "Design and Development of Fuzzy Expert System for Diagnosis of Hypertension," in 2011 Second International Conference on Intelligent Systems, Modelling and Simulation, 2011, pp. 113-117.

[9] M. Hamilton, “A rating scale for depression,” J. Neurol. Neurosurg. Psychiatry, vol. 23, pp. 56-62, 1960.

[10] Oktopanda, “A Study Approach of Decision Support System with Profile Matching," Int. J. Recent Trends Eng. Res., vol. 3, no. 2, pp. 31-44, 2017.

[11] T. Kristiana, "Penerapan Profile Matching untuk Penilaian Kinerja Pegawai Negeri Sipil (PNS),” J. Pilar Nusa Mandiri, vol. XI, no. 2, pp. 161-170, 2015.

[12] Afijal, M. Iqbal, Najmuddin, and Iskandar, "Decision Support System Determination for Poor Houses Beneficiary Using Profile Matching Method,” Acad. Res. Int., vol. 5, no. 4, pp. 385-394, 2014.

[13] H. A. Hasibuan, R. B. Purba, and A. P. U. Siahaan, "Productivity Assessment ( Performance , Motivation , and Job Training ) using Profile Matching,” SSRG Int. J. Econ. Manag. Stud., vol. 3, no. 6, pp. 73-77, 2016.

[14] R. Nasriyah, Z. Arham, and Q. Aini, "Profile matching and competency based human resources management approaches for employee placement decision support system (case study),” Asian J. Appl. Sci., vol. 9, no. 2, pp. 75-86, 2016.

[15] E. Meijering, “A Chronology of Interpolation: From Ancient Astronomy to Modern Signal and Image Processing," Proc. IEEE, vol. 90, no. 3, pp. 319-342, 2002. 